\title{
THE SERVICE BEHIND THE SERVICE: Sensegiving in the Service Economy
}

\author{
Neil C. Ramiller \\ School of Business Administration \\ Portland State University \\ Portland, OR U.S.A. \\ Mike Chiasson \\ Department of Management Science \\ Lancaster University \\ Lancaster, U.K.
}

\begin{abstract}
In this modest essay, we reflect on the crucial role of sensegiving, and hence sensemaking, in the creation of IT-enabled service encounters. "Creation" has two meanings here: (1) the design of repeatable (reproducible) IT-enabled services, and (2) the on-going coproduction of IT-enabled service events by service providers and recipients. Indeed, we will argue that the sense given by diverse and role-differentiated actors constitutes in its own way a crucial and pervasive service that enables services in the more familiar sense. Sensegiving, as a "service behind the service," is of particular salience when it comes to novel IT-enabled services, because of the challenges posed by their innovative character. As a practical matter, we are especially interested in how failures in the delivery of innovative services can be caused by shortfalls in sensemaking and sensegiving, and how the difference between successful and failed service outcomes commonly turns on choices made during the design of IT-enabled service systems. These designs either recognize and embrace, or marginalize and ignore, the required and novel sensemaking and sensegiving of employees and customers. We also recognize that system designs are rarely determinative (as constraining as they might prove to be), and that service outcomes will still depend on the variable appropriation of information technology in real situations of practice. We conclude our essay by outlining some research directions in IT-enabled service delivery, arising from these issues.
\end{abstract}

Please use the following format when citing this chapter:

Ramiller, N. C., and Chiasson, M., 2008, in IFIP International Federation for Information Processing, Volume 267, Information Technology in the Service Economy: Challenges and Possibilities for the $21^{\text {st }}$ Century, eds. Barrett, M., Davidson, E., Middleton, C., and DeGross, J. (Boston: Springer), pp. 117-126. 
Keywords Sense-making, sense-giving, service delivery, coproduction, information systems design

\section{INTRODUCTION}

The concept of service has enjoyed increasing prominence in discourse about the emerging global economy. Indeed, as the call for papers for this working conference observes, growth in the service economy has been profound and global in its scope. Services are of particular interest to our research community because of the role that information technologies are playing in the transformation of the service sector, through their support of innovative business models, work practices, conversions of products into services, and amplifications of traditional products and services with information.

In innovations of these kinds, there is always much to be learned and decided about the role that information technology can and ought to play. In light of the learning involved, we reflect in this essay on the crucial place that participants' sensemaking and sensegiving hold in the creation of new and reconstituted service encounters. We will argue that sensegiving, in particular, is usefully conceptualized as a service in its own right, which enables the design and delivery of services in the more familiar sense. While sensegiving has always played such a role in services, we will suggest that it is particularly salient where novel IT-enabled services are concerned. This is the case in part because of the demands that innovation makes on sensemaking (Swanson and Ramiller 2004). But it is also true because the potential of IT to transform services presents management (especially) with choices concerning how much to take the sensemaking and sensegiving of participants involved in service delivery into account during technology design and operation.

Analytically, we will locate sensegiving, as this "service behind the service," in two interrelated domains. Sensegiving is necessarily an activity in the organizational design of repeatable and reproducible IT-enabled services. It is also an aspect of the communicative exchange that takes place between service provider and service recipient during their coproduction of actual service events. What is of interest and importance, for both practice and research, is that sensegiving can be more or less effective during service delivery. Effectiveness, in-turn, can depend on the choices made during the design of information technology in recognizing and allowing, or marginalizing certain forms of sensemaking and sensegiving between employees and customers. Technological designs also influence the amount of "play" that the participants in service encounters can find to improvise, whether by means of, or in spite of, the technical facilities that are provided.

Our discussion proceeds as follows. First, we consider in further depth how sensemaking and sensegiving fit in a fundamental way into the constitution of services. We then explore the alternative fates of sensegiving, relative to its role in the kinds of service transformations that are appearing and helping to define the service economy. We follow up, then, by considering the relationship between sensegiving and effective service delivery. While conceding the complex and problematic relationship between technological constraint and allowance, and service effectiveness, we also note that its overlapping and sometimes conflicting meanings help illuminate the important part that 
power, politics, and participation play in service design (as process) and service designs (as outcomes). We conclude our essay by reflecting, in a preliminary way, on how academic research might help illuminate sensemaking and sensegiving in various ITenabled services.

\section{SENSEMAKING AND SENSEGIVING AS SERVICE}

As the call for papers observes, service activities entail "a negotiated and often cogenerated exchange between a provider and a...customer in the provision of largely intangible assets." The provider and the recipient, acting in concert with and by means of other actants which may include information technologies of one kind or another (Callon 1986), coproduce a service within institutionalized and communicative rules and norms. These rules help make the encounter stable, efficient, understandable, and predictable to the participants - an important part of service delivery. They also make it possible for us to recognize more or less discrete categories of services (e.g., software support, catalog ordering, healthcare provision, hospitality services, distance education, and so on) which are also important in shaping provider and customers expectations. With increasing levels of standardization, often at the initiative of the provider using information technology, the service encounter can become even more predictable. But even in the strictest of institutional and standardized domains, every service event entails some degree of sensemaking and sensegiving on the participants' part, even if this is undertaken mainly to apply, and signal compliance with, the established norms. Especially in those cases where there is innovation in a service, or at least a lack of familiarity, which for a service recipient can amount to much the same thing as innovation (Rogers 2003), service sensemaking and sensegiving naturally become much more significant and demanding.

Sensemaking is as it sounds: making sense of things, where understanding is as yet lacking (Weick 1995). Sensemaking should not be construed as passive, but as integrally joined with action in cycles of enactment-and-sensemaking that shape as well as interpret reality. In the organizational context, then, sensemaking is "activity that talks events and organizations into existence" (Weick et al. 2005, p. 413), a fact that further "suggests that patterns of organizing are located in the actions and conversations that occur on behalf of the presumed organization and in the texts of those activities that are preserved in social structure" (ibid).

The notion that services are coproduced by provider and recipient further evokes an important aspect of sensemaking: that one party's interpretations are built on the interpretations of others, to a large degree. In this regard, the call for papers notes, "Services exchange often involves many complex combinations of both explicit and tacit knowledge as providers and customers attempt to collectively coordinate and integrate their knowledge in service delivery." Such combinations, coordination, and integration evoke the sensemaking and sensegiving that are integral in the live constitution of the service encounter, as each participant must interpret context, objectives, tasks, means, and the evidence (from speech and action) concerning others' interpretations, while signaling to others their own interpretations. 
Sensemaking is, therefore, fundamentally social in character. In describing the actions of an experienced nurse who is trying to find the language that will trigger a doctor's decision making in a critical medical event, Weick and his colleagues remark,

The...nurse absorbs the complexity of the situation...by holding both a nurse's and doctor's perspectives of the situation while identifying an account of the situation that would align the two. What is especially interesting is that she tries to make sense of how other people make sense of things, a complex determination that is routine in organizational life (Weick et al. 2005, p. 413).

The enactment side of sensemaking in a social context is often accomplished by sensegiving, which is "undertaken to create meanings for a target audience... the content of sensegiving (present versus future image) and the target (insider versus outsider) affect how people interpret the actions they confront" (Weick et al. 2005, p. 416). ${ }^{1}$

In the singular service event, the participants typically will, to the extent possible, construct the emergent social reality using familiar means. However, where novelty is relatively high, the sensemaking and sensegiving that are required may increase substantially. This is true in the constitution of the particular service event, but can also return to the general invention or reinvention of the service practice in the first place. Figure 1 suggests the added complexity we must take into account.

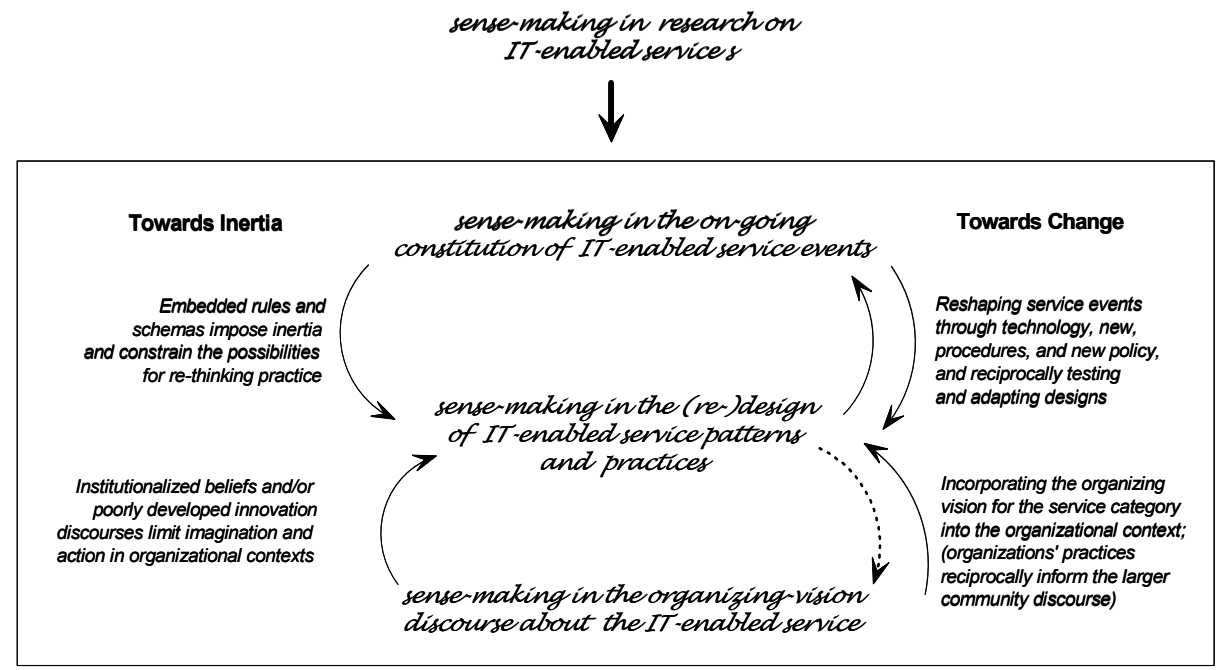

Figure 1. The Stratigraphy of Sensemaking (and Sensegiving) in IT-Enabled Services

${ }^{1}$ With sensegiving, the loop must of course be closed by the recipient being open to incorporate that gift of sense into their own sensemaking. Boland and Tenkasi have noted this in connection with their concept of perspective-taking. They state, "producing knowledge to create innovative products and processes... requires the ability to make strong perspectives within a community, as well as the ability to take the perspective of another into account" (Boland and Tenkasi 1995, p. 350). 
Here we call attention to the middle layer in Figure 1. As a service-behind-theservice undertaken in the cause of new designs (and redesigns) in some service domain, sensemaking (the production aspect) and sensegiving (the delivery aspect) together can change how the organization and its members see that domain. The goal is to make the change more sensible and legitimate, and hence as a practical matter, more tractable. Of course, in doing this, sensemaking and sensegiving also prepare those actors for action that help them shape the material reality during actual service encounters.

Note that the creation of an information system to enable one or more new or transformed services is itself a kind of service rendered to others by the systems development project team. And many a project success or failure has hinged on the quality of the coproduction of sense between the largely "technical" project team members and the people in the business. Of course, this is far from a matter of making sense only of the technology's role. It is also a matter of constructing or reconstructing the cognitive and behavioral patterns, and the deeper structures of meaning and legitimacy which enable service experts to map customer requests and needs into cognitive and procedural templates that deliver the correct service quickly, and in ways that are consistent with agreed patterns of identity and ethical appropriateness.

What we have just said might be read as a claim for a top-down relationship from service design to service event, but this is not our intention. Note the reciprocal arrows in Figure 1. Yes, new service designs, in the form of technology and organizational policies and procedures, surely affect the production of the events. But these designs, as we have already suggested, are of a different nature from the corresponding service events themselves. Accordingly, the coproduction of the service by provider and receiver on the ground is always, in part, an improvisational act. Moreover, in the right circumstances, reflection on completed service events and their outcomes can lead to changes in policies and procedures that may even bring about an adaptive redesign of the technology. More subtly and subversively, reflective action may cause the technology's selective and "unfaithful" appropriation (DeSanctis and Poole 1994), through, for example, work-arounds and other activities which are invoked in order to provide a desirable and needed service to clients.

Figure 1 includes yet another layer in which sensemaking and sensegiving matter to the IT design and service delivery, and this is wider public discourse on IT-enabled services. This is where the organizing vision for the IT-enabled service arises, as Swanson and Ramiller (1997) would label it. The public discourse is not idle chatter, nor simply a playground for pundits and journalists, but rather helps to define how people and their organizations think substantively about the possibilities, while also lending normative force to the service innovation (Swanson and Ramiller 1997, 2004). In this way, the public discourse can have an institutionalizing effect that helps to move the innovation toward a taken-for-granted status, even as it serves as a resource in an organization's local sensemaking. ${ }^{2}$ The universal usefulness of the public discourse, however, is not a given. It may be immature, or poorly developed for a particular application or industry, or it may be poorly developed for a particular organization's goals and existing practices

${ }^{2}$ Institutionalization occurs "where societal expectations of appropriate organizational form and behavior come to take on rule-like status in social thought and action" (Covaleski and Dirsmith 1988, p. 562). 
(Willis and Chiasson 2007), or it may encourage unmindful innovation (Swanson and Ramiller 2004). The upshot, then, is that the public discourse will sometimes fail to adequately inform and support an organization's local efforts in service design.

In summary, sensemaking and sensegiving together constitute an indispensable service in the (re)production of actual service events and in the transformation of service patterns or designs. Sensemaking and sensegiving are also integral to the broader institutional discourse about IT-enabled services and various service categories. In terms of a subject matter of concern to a particular academic community, attention to this servicebehind-the-service can reasonably focus on the sense that can, will, and might be made about the information technology that helps (or restricts) the delivery of specific service events, and the designs, patterns, and concepts of service.

\section{THE FATE OF SENSEGIVING IN CONTEMPORARY SERVICE TRANSFORMATIONS}

So, in focusing our attention in this way, what do we see? While this may be largely a matter for empirical research to decide, we would like to identify what we believe are some general and possible tendencies. We propose that, more commonly than not, the emphasis in information technology design within service industries has been on the restriction of individual and collective sensemaking, in order to rationalize and freeze past or to reengineer future practices in order to define fixed, reliable, and measurable services. ${ }^{3}$ We have all personally experienced, in many of our own service encounters, how IT may also decrease and hamper the provider's capability and flexibility in responding to the true complexity of the recipients' needs. We believe that management's first (and sometimes, worst) inclination has been to use technology to eliminate the numerous and "idiosyncratic" approaches that employees have cultivated "haphazardly" like weeds in an untended garden (see Head 2003). In short, we view the trend in ITenabled service delivery as being closely akin to management's historical choices in machine automation (Noble 1984).

Moving beyond this tendency to naturalize this mechanistic strategy through a rhetoric of technological determinism, ${ }^{4}$ alternatives are available that proceed from a different set of assumptions about the range of sensemaking and sensegiving allowed and supported during service events. One possibility is a shift in system design away from a closing-down of sensemaking toward the development of systems that actively support it. This has both process and design aspects.

When it comes to the processes of specifying, designing and configuring IT to enable service production, a system that is intended to support a more active, on-going and future sensemaking will require deeper and broader participation in the sensemaking that

${ }^{3}$ In the first case, this can be likened to the popular expression "paving the cowpaths," and in the latter case to "building a highway to the future." In both cases, the image is one of linear, predictable, and determinative process.

4، [N] aturalization gives to particular ideological representations the status of common sense, and thereby makes them...no longer visible as ideologies" (Fairclough 1995, p. 42). 
occurs during IT design itself. That is, if empowerment in sensemaking and sensegiving during actual service situations is the objective, then it stands to reason that a similar empowerment will be needed in the creation of the system that will help to enable such outcomes. This may point toward more "agile" socio-technical strategies that can support the meaningful and extended engagement of the future system users (Cockburn 2002), and leverage their insights about practice in a way that fosters flexibility in design (Brown and Duguid 2000). This is in contrast to more traditional structured approaches and to development strategies that are commonly reflected in ERP and business process reengineering, which sequester and limit user participation.

When it comes to the content of technology designs, our basic position is that the particulars of design will typically best be left to those who know the work. Nevertheless, we have some general suggestions. Technological and system designs which allow and foster technical change in order to explore and support new service sensegiving and sensemaking practices would be increasingly desired. Often in sharp contrast, today's enterprise resource planning systems, despite considerable diversity in modularity and implementation options, appear to largely close-down and lock into place particular service practices (Head 2003). This is especially true where technology designers consider service primarily to be about the legitimized handling and entry of data across an assembly-line of personnel, instead of as a source of information and organizational memory that could help in supporting the development and delivery of a successful service outcome.

In addition to supporting both current and future service delivery possibilities, information technology infrastructures need to be open to change and modification, perhaps by the individuals and groups exploring and creating new service patterns from novel sensegiving and sensemaking events. Design will need to focus less on the specific information and programs to support and freeze current service delivery, but on an infrastructure that will allow a reshaping of specific data structures, content, and user access to support revised service delivery (Chiasson and Green 2007).

One way to consider this theoretically is to consider system development as a task to design and build boundary objects (Star and Griesemer 1989), which allow valueadded exchange across the heterogeneous interests of producers and suppliers. Here, boundary objects would support not only support-specific service events, which always involve some form of sensemaking and giving between producer and client, but also facilitate sensemaking and sensegiving toward new service encounters and service designs which support these more systematically.

In making the claims about the common restriction of sensemaking during current system design, and having spoken broadly in favor of empowerment and against automation and for sensemaking and sensegiving, we will certainly also concede that there is much to be said for efficiency and consistency in service, and for the standardization that is often required to realize it. The challenge, then, is that the various approaches to IT design in the support of service effectiveness may not appear commensurate. Does effectiveness mean the efficiency (speed, resource consumption) and consistency with which services are rendered? Does it mean the range of problems that can be solved, including the numerous exceptional cases? How does resiliency in service delivery figure into effectiveness? Do feelings of empowerment and satisfaction on the provider's and/or the recipient's part matter to the service outcome? 
These overlapping and apparently conflicting meanings point to the fact that service effectiveness is, to a degree, a question of consistency and change - where particular service patterns at some level and in certain circumstances can be dealt with quickly and efficiently, to the satisfaction of everyone. Effective service delivery in these circumstances, nevertheless, still depends on the active engagement and sensing of the producer and consumer in order to identify which efficient service requires delivery. In other new and novel circumstances, however, expanded sensemaking and giving needs to be possible in order to deal with unique situations, and the required novelty needs to be technologically supported in order to allow for this mindful deviation.

At the same time, it must be recognized that the supported services and the extent of mindful deviation also depends on whose interests are being served, and, to some extent, whose ox may be gored (which sadly, more often than not, is the customer's). There is, in short, an element of power and politics involved in the design of technology in the delivery of services. The prerogatives of sensegiving at the design stage may have an important effect on the sensemaking and sensegiving that are subsequently granted to others, in great part because of the way that "power is expressed in acts that shape what people accept, take for granted, and reject" (Weick et al. 2005, p. 418).

\section{TOWARD RESEARCH: MAKING SENSE OF SENSEGIVING AS SERVICE}

We have argued here that the task of designing and applying information technology in the delivery services is, in great part, a means to support service sensemaking and sensegiving. These design activities can themselves be considered as a kind of servicebehind-the-service, where sense-making and sensegiving about the tools and techniques to support many actual service encounters are considered. Moreover, the quality of this service-behind-the-service in any particular case will depend upon interactions among the organization's service design, participants' situational appropriation of that design, and the larger public discourse on the possibilities for service innovations (Figure 1 summarizes these interactions).

Figure 1 also identifies a place for academic research as its own kind of service in sensemaking and sensegiving. The following are preliminary ideas, but we would suggest that future research might usefully address any of the layers shown in the figure. For example, researchers might study close-up the sensemaking work of participants as they cocreate on-going service events using IT, or explore the sensemaking of diverse project members in the course of initiatives to redesign service categories and the creation of new service patterns. Researchers could also experiment with alternative modes of organizing and allocating opportunities for sensegiving in design projects, or study the organizational uptake and utilization of public discourses on service innovations in local sensemaking and legitimation activities. Finally, researchers could be involved in identifying and evaluating the implications for sensemaking and sensegiving of various technical design innovations, or in identifying alternative appropriations in practice.

In all of these research areas, making sense of the participants' own production of sense can be the foundation for meaningful service that the researchers themselves can provide. The trick, then, will be to create opportunities for academic sensegiving that can 
help produce improvements in IT-enabled practice, specifically through a guided concern for the sensegiving of the practitioners themselves. Again, this is not to claim that sensemaking and sensegiving have only just lately become important in the service domain. Rather, we hope to be convincing that these very old social processes deserve our community's refreshed attention, especially if we are to move beyond simplistic and breathless enthusiasm for the service economy, and to arrive instead at a critical understanding that embraces the variable realities of participation, power, design, and outcomes associated with the IT-enabled services.

\section{References}

Boland, R. J., Jr., and Tenkasi, R. V. 1995. "Perspective Making and Perspective Taking in Communities of Knowing," Organization Science (6:4), pp. 350-372.

Brown. J. S., and Duguid, P. 2000. "Balancing Act: How to Capture Knowledge Without Killing It," Harvard Business Review (78:3), May-June, pp. 73-80.

Callon, M. 1986. "Some Elements of the Sociology of Translation: Domestication of the Scallops and the Fishermen of St. Brieuc Bay," in Power, Action and Belief: A New Sociology of Knowledge?, J. Law (ed.), London: Routledge, pp. 196-223.

Chiasson, M., and Green, L. W. 2007. "Questioning the IT Artefact: User Practices That Can, Could, and Cannot Be Supported in Packaged-Software Designs," European Journal of Information Systems (16), pp. 542-554.

Cockburn, A. 2002. Agile Software Development, Boston: Addison-Wesley.

Covaleski, M. A., and Dirsmith, M. W. 1988. "An Institutional Perspective on the Rise, Social Transformation, and Fall of a University Budget Category," Administrative Science Quarterly (33), pp. 562-587.

DeSanctis, G. R., and Poole, M. S. 1994. "Capturing the Complexity in Advanced Technology Using Adaptive Structuration Theory," Organization Science (5:2), pp. 121-147.

Fairclough, N. 1995. Critical Discourse Analysis: The Critical Study of Language, London: Longman.

Head, S. 2003. The New Ruthless Economy: Work and Power in the Digital Age, Oxford, UK: Oxford University Press.

Noble, D. F. 1984. Forces of Production: A Social History of Industrial Automation, New York: Knopf.

Rogers, E. M. 2003. Diffusion of Innovations ( $\left.5^{\text {th }} \mathrm{ed}.\right)$, New York: Free Press.

Star, S. L., and Griesemer, J. R. 1989. "Institutional Ecology, 'Translations' and Boundary Objects: Amateurs and Professionals in Berkeley's Museum of Vertebrate Zoology, 19071939," Social Studies of Science (19:3), pp. 387-420.

Swanson, E. B. and Ramiller, N. C. 1997. "The Organizing Vision in Information Systems Innovation," Organization Science (8:5), pp. 458-473.

Swanson, E. B. and Ramiller, N. C. 2004. "Innovating Mindfully with Information Technology," MIS Quarterly (28:4), pp. 553-583.

Weick, K. E. 1995. Sensemaking in Organizations, Thousand Oaks, CA: Sage Publications.

Weick, K. E., Sutcliffe, K. M., and Obstfeld, D. 2005. "Organizing and the Process of Sensemaking," Organization Science (16:4), pp. 409-421.

Willis, B., and Chiasson, M. 2007. "Do the Ends Justify the Means? A Gramscian Critique of the Processes of Consent During an ERP Implementation," Information Technology and People (20:3), pp. 212-234. 


\section{About the Authors}

Neil Ramiller is the Ahlbrandt Professor in the Management of Innovation \& Technology at Portland State University's School of Business Administration. Neil holds a Ph.D. from UCLA's Anderson School of Management. His primary research activities address the management of information-technology innovations, with a particular focus on the role that rhetoric, narrative, and discourse play in shaping innovation processes and negotiating multi-party interests within organizations and across interorganizational fields. He also conducts work on the social construction of information technology scholarship, and the implementation of the "linguistic turn" in information technology studies. Neil has presented his work at a variety of national and international conferences, and published articles in a number of journals, including Journal of the Association for Information Systems, MIS Quarterly, Information \& Organization, Information Technology \& People, Organization Science, Journal of Management Information Systems, and Information Systems Research. Neil can be reached at neilr@sba.pdx.edu.

Mike Chiasson is currently an AIM (Advanced Institute of Management) Innovation Fellow and a Senior Lecturer at Lancaster University's Management School, in the Department of Management Science. Before joining Lancaster University, he was an associate professor in the Haskayne School of Business, University of Calgary, and a postdoctoral fellow at the Institute for Health Promotion Research at the University of British Columbia. His research examines how social context affects IS development and implementation, using a range of social theories (actor network theory, structuration theory, critical social theory, ethnomethodology, communicative action, power-knowledge, deconstruction, and institutional theory). In studying these questions, he has examined various development and implementation issues (privacy, user involvement, diffusion, outsourcing, cyber-crime, and system development conflict) within medical, legal, engineering, entrepreneurial, and governmental settings. Most of his work has been qualitative in nature, with a strong emphasis on participant observation. Mike can be reached at m.chiasson@lancaster.ac.uk. 